\title{
Awareness of nutrient loss among Illinois corn farmers
}

\author{
G.S.W. Hoselton and M.A. Boerngen
}

\begin{abstract}
Nitrogen $(\mathrm{N})$ fertilizer runoff in the Mississippi River Basin contributes to a hypoxic zone in the Gulf of Mexico. Through efforts such as the Illinois Nutrient Loss Reduction Strategy, farmers are being challenged to voluntarily change production practices to limit the amount of $\mathrm{N}$ lost from their fields through runoff. Best management practices currently recommended to reduce nutrient loss include cover crops, optimal application timing, bioreactors, wetlands, and buffers. However, the adoption of new or unfamiliar farming practices such as these best management practices is inherently risky for farmers. In order to gain a more detailed understanding of how farmers perceive nutrient loss, and their willingness to voluntarily comply with nutrient loss reduction goals, a survey was designed and administered to approximately 3,850 members of the Illinois Corn Growers Association. The survey was designed in consultation with nutrient loss experts at the Illinois Corn Growers Association, whose membership was chosen because they would be most affected by regulation limiting $\mathrm{N}$ application timing or rates. Questions addressed farmers' demographics, nutrient loss concerns, and production practices related to reducing nutrient loss. Key findings from the 762 completed surveys include the importance placed on conservation practices in respondents' farming operations, a high level of concern about nutrient loss, and operational changes already made in response to those concerns. By providing insights on how farmers perceive and are responding to nutrient runoff, this study can contribute to efforts encouraging voluntary compliance with the goals of the Illinois Nutrient Loss Reduction Strategy.
\end{abstract}

Key words: agriculture—nutrient runoff-voluntary compliance

\begin{abstract}
Nutrient runoff in the Mississippi River Basin has caused a hypoxic "dead" zone in the Gulf of Mexico. Through voluntary efforts, Illinois farmers are being asked to help reduce nutrient loss from their agricultural land. The Illinois Nutrient Loss Reduction Strategy (Illinois NLRS) (Illinois EPA 2015) provides a framework for farmers to voluntarily reduce nutrient runoff in a coordinated and cost-effective manner to improve water quality. The Illinois NLRS was written by the Illinois Environmental Protection Agency (EPA) in collaboration with multiple industry groups to encourage voluntary compliance to reduce nutrient loss. These industry groups include the Illinois Corn Growers Association (ICGA), Illinois Farm Bureau, and the Illinois Department of Agriculture. This strategy was developed after
\end{abstract}

the USEPA wrote the 2008 Gulf Hypoxia Action Plan calling for the 12 states in the Mississippi River Basin to make a plan to reduce nutrient runoff into the Mississippi River and the Gulf of Mexico. The strategy does not call for new regulations for either point sources (industrial sources such as water treatment facilities) or nonpoint sources such as farm fields, but outlines a number of conservation practices that can be voluntarily implemented to reduce nutrient runoff. Point sources are required by the Illinois NLRS to have total maximum daily load (TMDL) waste load allocations. While the strategy does not have TMDL for nonpoint sources, it does have statewide reduction goals for nitrate $\left(\mathrm{NO}_{3}^{-}\right)$and phosphorus $(\mathrm{P})$ runoff. These goals are to reduce $\mathrm{NO}_{3}^{-}$runoff by $15 \%$ by 2025 and to reduce $\mathrm{P}$ runoff

Received June 23, 2020; Revised January 12, 2021; Accepted February 15, 2021; Published online June 14, 2021. by $25 \%$ by 2025 , with an eventual goal of $45 \%$ reduction in the loss of both $\mathrm{NO}_{3}^{-}$and $\mathrm{P}$ measured against the average annual loss of these nutrients during the years 1980 to 1996 (consistent with the baseline established by the Gulf Hypoxia Action Plan). The Chesapeake Bay watershed has a similar issue with nutrient loss into the bay, causing a hypoxic zone there as well. The Chesapeake Bay watershed measures $165,760 \mathrm{~km}^{2}(64,000$ $\left.\mathrm{mi}^{2}\right)$, with 150 major rivers and streams, and covers six states and the District of Columbia. The rivers and streams flowing into the bay have TMDLs regulating how much nutrient runoff flows into the bay (Chesapeake Bay Program 2012). This type of regulation could affect Illinois farmers if the state's nutrient loss goals are not met voluntarily.

Because they typically operate on thin profit margins, it is inherently risky for farmers to introduce new conservation practices into their existing farming operations due to the potential for new and unfamiliar practices to negatively impact their short-term financial returns. This becomes more concerning for renters, especially if they are not guaranteed to be operating the same land in subsequent years and therefore may never realize the full benefit of establishing those conservation practices. Bigelow et al. (2016) found that $60 \%$ of all Illinois farmland is renter-operated, and this high proportion of rented farmland may present a particular challenge in meeting nutrient loss reduction goals in Illinois.

The purpose of this study is to assess Illinois farmers' knowledge of the Illinois NLRS and to measure how they are addressing nutrient loss on the farmland they operate. The Illinois NLRS outlines a number of best management practices (BMPs), but there is little known about how farmers perceive nutrient loss and the efficacy of these practices. This study addresses that knowledge gap through a research survey in collaboration with the ICGA. Questions aim to reveal farmers' familiarity with the Illinois NLRS, what factors influence their decision-making when it comes to conservation practices and fertilizer application, their level

George S.W. Hoselton is a crop consultant with Nutrien, Minier, Illinois. Maria A. Boerngen (corresponding author) is an associate professor in the Department of Agriculture at Illinois State University, Normal, Illinois. 
of concern about nutrient loss, and how they are responding to those concerns.

\section{Materials and Methods}

A 24 question survey was developed to determine whether Illinois corn (Zea mays L.) farmers are concerned about nutrient loss and whether they are making changes in their practices in response to this issue. Questions pertained to farmers' demographics, nutrient loss concerns, and production practices such as nitrogen $(\mathrm{N})$ application timing. Six questions addressed farmers' demographics since farmer characteristics play a role in the decision-making process on the farm. Five questions pertained to nutrient loss in order to determine whether respondents believe there is a nutrient loss problem and if they believe they are contributing to it. One question addressed where farmers obtain their information about fertilizer input use, and 12 questions focused on farmers' use of conservation practices including their adoption of BMPs recommended by the Illinois NLRS.

The survey was designed using the Internet, Phone, Mail, and Mixed-Mode Surveys: The Tailored Design Method handbook (Dillman et al. 2014). The survey was constructed with assistance from staff members at the ICGA. Participants that were surveyed are members of the ICGA. This group of individuals was chosen because they would be most affected by regulation limiting $\mathrm{N}$ application timing or rates. Some ICGA members received survey materials via standard US mail and others by email, because in routine communication with its members the ICGA uses email addresses for over half of their members and uses home mailing addresses for the rest of their membership.

The creation of this survey was based on a pilot study completed by an undergraduate research assistant at Illinois State University. The student interviewed 30 farmers in McLean County, Illinois, to understand how farmers make their input use decisions and how familiar they are with the Illinois NLRS, and to determine farmers' level of concern about nutrient loss (Marks and Boerngen 2019). Criterion-related validity of the ICGA survey was established by this pilot study along with other research studies found during the review of literature such as Ritter (2012). The expertise the staff at the ICGA have with surveys routinely sent to the organization's membership establishes this survey's face validity and content validity. Following Illinois State University Institutional Review Board approval (\#2018-318), consistent with the recommendations of Dillman et al. (2014), ICGA members received survey prenotifications in early summer of 2018, with the survey following approximately two weeks later. A reminder was sent approximately two weeks after distribution of the survey. A little over one month later, ICGA members receiving electronic communication received an additional email reminder, with this reminder also posted on the ICGA website. This second reminder was only distributed via email because of time constraints in the ICGA office preventing another mailed reminder. All mailings and emails were sent directly from the ICGA, and ICGA members receiving electronic communication accessed the survey using the Qualtrics (Qualtrics, Provo, Utah) online survey platform. The survey was completed anonymously, with no trackers or identifiers that could reveal the respondents' identities. It was closed on November 5, 2018, after being open for 126 days. The survey results were analyzed using IBM SPSS Statistics 26 (IBM, Armonk, New York).

Descriptive statistics included frequency distributions and Chi-square tests of independence. Binomial logistic regression analyzed the potential effects of farmer demographics and perceptions on the implementation of operational changes in respondents' farming operations.

\section{Results and Discussion}

Of the 3,837 surveys that were distributed, 762 completed surveys were coded and recorded (472 mailed surveys and 290 electronic surveys), for a total response rate of $19.9 \%$. A majority of respondents indicated that their farming operation is grain only $(73.2 \%)$. Of the remaining respondents, all but one reported mixed grain and livestock operations (26.6\%).

Utilizing information from the USDA Economic Research Service and the 2017 Census of Agriculture (USDA ERS 2018a, 2018b; USDA 2019), survey respondents' demographics were compared to farmers across Illinois and the United States in order to verify that the study participants were representative of the general farming population. The majority of respondents indicated that they were 56 years of age or older (77.4\%), comparable to the average operator age in Illinois (57.8 years old) and the United States
(58.3 years old). The majority of both the survey respondents (56.7\%) and US farmers $(68 \%)$ have a high school education plus some college (the average education level of Illinois farmers was not available). Virtually all survey respondents (97.2\%) were male, slightly higher than both the Illinois (90.8\%) and US (86.3\%) farming populations. A large percentage $(65.1 \%)$ of respondents indicated that they rent the majority of the land on which they farm. In Illinois, approximately $58 \%$ of all farmland is operated by a renter, whereas $39 \%$ of farmland nationwide is tenant-operated.

In Illinois, the amount of nonpoint $\mathrm{NO}_{3}{ }^{-} \mathrm{N}$ loading differs across the state, and there are eight priority watersheds for addressing nutrient loss from agricultural nonpoint sources. North/central Illinois has the greatest amount of nutrient runoff in the state because of greater use of the land for agricultural purposes (Illinois EPA 2015). For the purpose of this study, figure 6.1 from the Illinois NLRS (Illinois EPA 2015) showing nonpoint $\mathrm{NO}_{3}^{-}$runoff, and the USDA crop reporting district map for Illinois (USDA NASS n.d.), were overlaid to create a north, central, and south region of the state at logical intersections between the two maps (figure 1). Survey respondents were asked to indicate in which county the largest percentage of their farmland is located (to account for those who farm in multiple locations), and those responses were then categorized by the north, central, and south regions to analyze geographic differences. There are 23 counties in the north region, 55 counties in the central region, and 24 counties in the south region, accounting for $22 \%, 60 \%$, and $18 \%$ of total Illinois farms, respectively (Kuethe 2019). This question received 743 responses with $34.1 \%$ from the north region, $57.7 \%$ from the central region, and $8.2 \%$ from the south region of Illinois.

As illustrated in table 1, the majority of respondents indicated that conservation practices are very or somewhat important in their farming operations (97.1\%), that they are very or somewhat familiar with the Illinois NLRS (66.1\%), that they are very or somewhat concerned about nutrient loss (79.3\%), and that they are very or somewhat concerned about the implementation of regulation limiting the timing or rate of $\mathrm{N}$ fertilizer application (88.1\%). Additionally, $90.9 \%$ of respondents believe that nutrient loss has a negative impact on the environ- 
ment, and $79.4 \%$ have made changes to their farming operations because of their concern about nutrient loss. Chi-square tests of independence were calculated evaluating the importance of conservation practices to respondents and their implementation of operational changes, based on the region in which they farm. No significant relationship was found between region and the importance of conservation practices $\left[X^{2}(4)=\right.$ $1.909, p>0.05]$, nor between region and changes made to the farming operation $\left[X^{2}(2)=2.530, p>0.05\right]$. The importance placed on conservation practices and the implementation of operational changes both appear to be independent of region.

Chi-square tests of independence were calculated comparing the perspectives on nutrient loss and conservation among owner-operators and tenant-operators. No significant relationship was found between land tenure and the importance placed on conservation practices $\left[X^{2}(2)=2.103, p>\right.$ 0.05], familiarity with the Illinois NLRS $\left[X^{2}(3)=1.912, p>0.05\right]$, level of concern about nutrient loss $\left[X^{2}(3)=5.430, p>\right.$ $0.05]$, changes made to the farming operation because of nutrient loss concerns $\left[X^{2}(1)\right.$ $=1.173, p>0.05]$, or concerns about the implementation of regulations limiting $\mathrm{N}$ application timing or rates $\left[X^{2}(3)=4.369, p\right.$ $>0.05]$. The way Illinois corn farmers perceive and respond to nutrient loss appears to be independent of land tenure.

Binomial logistic regression evaluates whether a dichotomous dependent variable can be predicted based on categorial independent variables. This method was utilized to analyze the implementation of operational changes (a yes or no dependent variable) in response to concerns about nutrient loss represented by the following independent variables: farmer age (under 56 years or 56 years or older); education (less than a bachelor's degree or bachelor's degree or higher); region (as previously described); and importance of conservation practices, level of concern about nutrient loss, familiarity with the Illinois NLRS, and level of concern about regulation (as defined in table 1). The logistic regression was statistically significant $\left[X^{2}(16)=140.856, p<0.01\right]$. Decreasing farmer age, increased concern about nutrient loss, increased familiarity with the Illinois NLRS, and increased concern about regulation were associated with a greater likelihood of changes having been made to the respondents' farming operation.

Table 2 shows where respondents obtain their information on fertilizer input use. Because respondents could select more than one answer, the percentages add up to more than $100 \%$. The most frequently selected information sources were fertilizer/ seed salesmen, chosen by $72.6 \%$ of respondents. Numerous collaborations among agricultural input suppliers and industry organizations encourage voluntary adoption of production practices to reduce nutrient loss. For example, the Illinois $4 \mathrm{R} 4 \mathrm{U}$ Partnership ("Right Source, Right Rate, Right Time, and Right Place") includes the Illinois Farm Bureau; county Farm Bureau chapters; GROWMARK, Inc.; and local FS Member Companies (The Fertilizer Institute 2016). Another example is the "Illinois 4R

\section{Figure 1}

North, central, and south respondent regions.

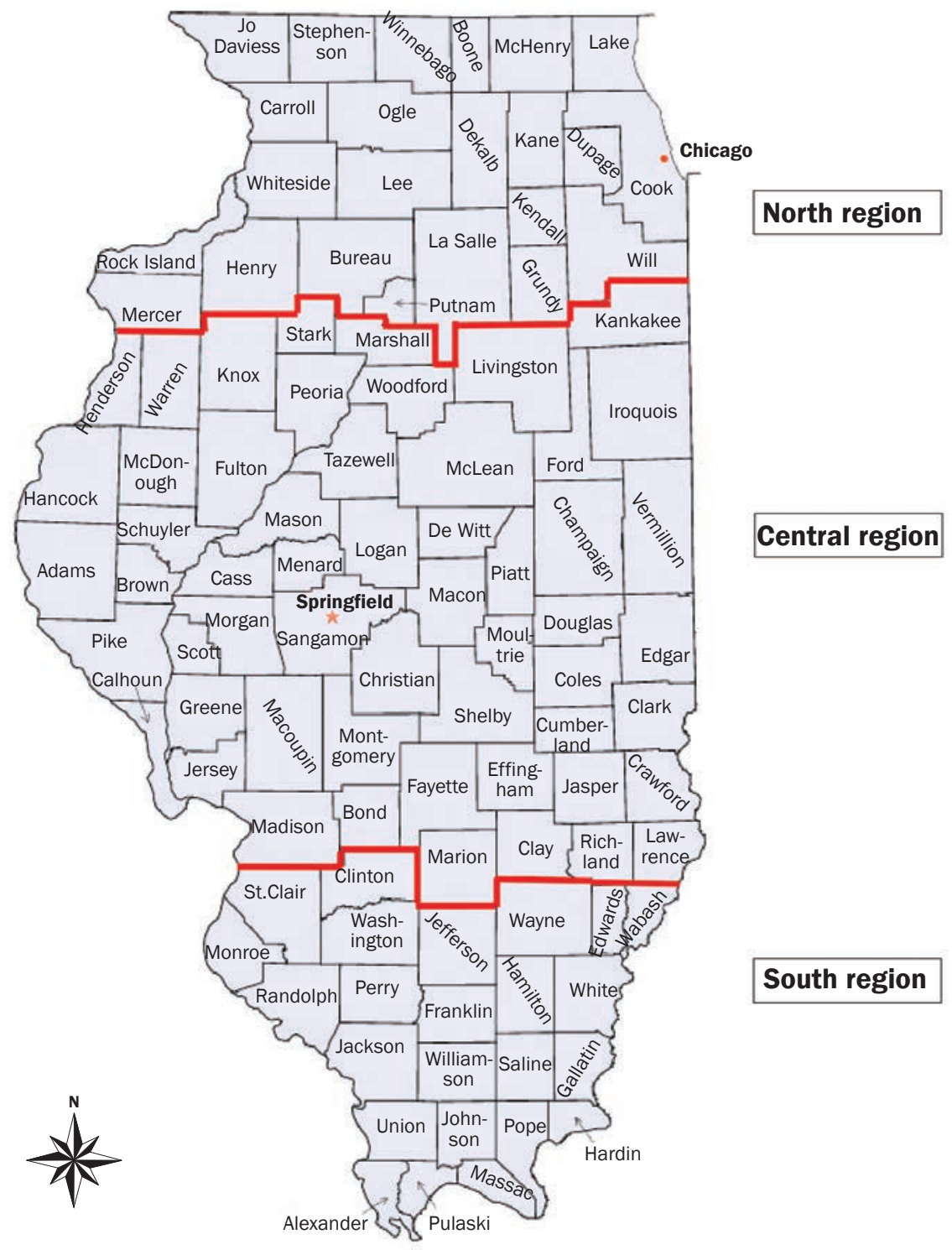


Code of Practice" adopted by the Illinois Fertilizer \& Chemical Association (IFCA). The IFCA represents agricultural retailers who serve farmer-customers in all parts of Illinois, and encourages its member companies to "[commit] to a 4R Code of Practice" including educating customers on sound $\mathrm{N}$ management and promoting the implementation of $4 \mathrm{R}$ practices (Illinois Fertilizer \& Chemical Association n.d.). The trust that farmers place in the advice given by input sales personnel suggests that these collabora- tive efforts may be valuable in achieving the goals of the Illinois NLRS.

\section{Summary and Conclusions}

Illinois corn growers are being challenged to voluntarily reduce the amount of nutrient runoff from farm fields within the framework of the Illinois NLRS. This study found that Illinois corn growers are aware of, concerned about, and responding to nutrient loss from their fields. Over $90 \%$ of respondents believe that nutrient loss has a negative

\section{Table 1}

Respondents' perspectives on conservation and nutrient loss.

\begin{tabular}{lcc}
\hline Perspective & Number & $\%$ \\
\hline Importance of conservation practices in respondents' farming operations $(n=758)$ & \\
Very Important & 511 & 67.4 \\
Somewhat Important & 225 & 29.7 \\
Slightly Important & 22 & 2.9 \\
Not at all important & 0 & 0.0 \\
\hline Respondents' familiarity with the Illinois Nutrient Loss Reduction Strategy $(n=753)$ & 17.0 \\
Very familiar & 128 & 49.1 \\
Somewhat familiar & 370 & 20.1 \\
Slightly familiar & 151 & 13.8 \\
Not at all familiar & 104 & \\
\hline Respondents' level of concern with nutrient loss $(n=754)$ & 41.1 \\
Very concerned & 310 & 38.2 \\
Somewhat concerned & 288 & 17.8 \\
Slightly concerned & 134 & 2.9 \\
Not at all concerned & 22 & 54.1 \\
\hline Respondents' regulation concerns due to nutrient loss $(n=752)$ & 34.0 \\
Very concerned & 407 & 10.5 \\
Somewhat concerned & 256 & 1.3 \\
Slightly concerned & 79 & 90.9 \\
Not at all concerned & 10 & 9.1 \\
\hline Respondents' perception of negative environmental impact from nutrient loss $(n=734)$ \\
Yes & 667 & \\
No & 67 & \\
\end{tabular}

\section{Table 2}

Respondents' information sources for fertilizer input use decisions.

\begin{tabular}{lcc}
\hline Source & Number & $\%$ \\
\hline Potential sources $(n=762)$ & & \\
Fertilizer/seed salesman & 553 & 72.6 \\
Certified crop advisors & 383 & 50.3 \\
University research/extension & 321 & 42.1 \\
Publications & 275 & 36.1 \\
Maximum return to nitrogen calculator & 153 & 20.1 \\
Other & 79 & 10.4
\end{tabular}

impact on the environment, nearly $80 \%$ are very or somewhat concerned about nutrient loss, and nearly $80 \%$ have already made changes to their farming practices because of nutrient loss.

This study found that conservation practices are clearly important to Illinois corn growers. This is important because implementation of the BMPs outlined in the Illinois NLRS will help the farming community comply with its nutrient loss reduction goals. A majority of survey respondents reported being somewhat to very familiar with the Illinois NLRS, indicating that they are aware of the state's framework for addressing the nutrient runoff problem. This study found no difference in perception or concern about nutrient loss or the implementation of operational changes in response to those concerns among owner-operators and tenant-operators. Farmers under the age of 56 and those who express a higher level of concern about nutrient loss, a greater familiarity with the Illinois NLRS, and a higher level of concern about regulation limiting $\mathrm{N}$ application timing or rates, are more likely to have made changes to their farming operations. The majority of respondents identified fertilizer/seed salesmen as their trusted source of fertilizer input use, suggesting that efforts already underway such as the Illinois $4 \mathrm{R} 4 \mathrm{U}$ Partnership and the Illinois 4R Code of Practice may be effective in further informing farmers of the nutrient reduction goals of the Illinois NLRS and encouraging voluntary adoption of production practices to reach those goals.

Farmers' attitudes are shaped by past experiences (van Winsen et al. 2014), so those that are more concerned with losing nutrient loss may have been affected by it in the past. In the present, the hypoxic zone in the Gulf of Mexico continues to grow each year from nutrient runoff in the Mississippi River, and Illinois corn producers appear to be well informed of, and responsive to, this issue. The Illinois NLRS outlines ambitious nutrient loss reduction goals for 2025, which gives approximately a decade for achievement from the time the Illinois NLRS was released. Voluntary nutrient loss reduction is vital if farmers wish to avoid fertilizer regulation being implemented. An extension of this study will specifically address the adoption of the BMPs recommended in the Illinois NLRS, and the obstacles farmers face when implementing them. 


\section{Acknowledgements}

We are grateful to the staff of the Illinois Corn Growers Association and Michael Barrowclough (assistant professor, Illinois State University, Normal, Illinois) for their assistance. Funding for this project was provided by USDA National Institute of Food and Agriculture-Agriculture and Food Research Initiative Food Security Program Grant 2016-68004-24769.

\section{References}

Bigelow, D., A. Borchers, and T. Hubbs. 2016. U.S. Farmland Ownership, Tenure, and Transfer, EIB-161. Washington, DC: USDA Economic Research Service.

Chesapeake Bay Program. 2012. State of the Chesapeake Bay and its Watershed: A Report to the Citizens of the Bay Region. Annapolis, MD: US Environmental Protection Agency.

Dillman, D.A., L.M. Christian, and J.D. Smyth. 2014. Internet, Phone, Mail, and Mixed-Mode Surveys: The Tailored Design Method. Hoboken, NJ: Wiley.

The Fertilizer Institute. 2016. Illinois 4R4U Partnership Launched. Arlington, VA: The Fertilizer Institute https://nutrientstewardship.org/4r-news / illinois-4r4u-partnership-launched/.

Illinois EPA (Environmental Protection Agency). 2015. Illinois Nutrient Loss Reduction Strategy. Springfield, IL: Illinois Department of Agriculture. http://www.epa.illinois.gov/topics/waterquality/watershedmanagement/excess-nutrients/ nutrient-loss-reduction-strategy-index.

Illinois Fertilizer \& Chemical Association. n.d. Illinois 4R Code of Practice. Bloomington, IL: Illinois Fertilizer \& Chemical Association. https://www.ifca.com/4R/Code.

Kuethe, T. 2019. Changes in Farms and Farmland in Illinois. Farmdoc Daily (9):76. Champaign, IL: Department of Agricultural and Consumer Economics, University of Illinois at Urbana-Champaign. https://farmdocdaily. illinois.edu/2019/04/changes-in-farms-and-farmlandin-illinois.html.

Marks, B., and M.A. Boerngen. 2019. The farming community's perspective on nutrient loss reduction. Agricultural \& Environmental Letters 4:190004 https://doi.org/10.2134/ael2019.02.0004

Ritter,T.E. 2012. Exploring the Relationship between Risk Perception and Farmer Nutrient Management Decisions. Master's thesis, Ohio State University. http://rave. ohiolink.edu/etdc/view?acc_num=osu1343243182.

USDA. 2019. 2017 Census of Agriculture. Washington, DC: USDA. https://www.nass.usda.gov/Publications/ AgCensus/2017/\#full_report.

USDA ERS (Economic Research Service). 2018a. Farm Household Income and Characteristics. Washington, DC: USDA ERS. https://www.ers.usda.gov/data-products/ farm-household-income-and-charatcteristics/.

USDA ERS. 2018b. State Fact Sheets. Washington, DC: USDA ERS. https://data.ers.usda.gov/reports. aspx?StateFIPS $=17 \&$ StateName $=$ Illinois $\&$ ID $=17854$
USDA NASS (National Agricultural Statistics Service) n.d. District and County Boundary Maps by State. Washington, DC: USDA NASS. https://www. nass.usda.gov/Charts_and_Maps/Crops_County/ boundary_maps/il.gif.

van Winsen, F., Y. de Mey, L. Lauwers, S. Van Passel, M. Vancauteren, and E. Wauters. 2016. Determinants of risk behaviour: Effects of perceived risks and risk attitude on farmer's adoption of risk management strategies. Journal of Risk Research 19(1):56-78. 